\title{
Effect of prostaglandin analogs on matrix metalloproteinases and tissue inhibitor of metalloproteinases in eyelid muscle specimens
}

This article was published in the following Dove Press journal:

Clinical Ophthalmology

\author{
Sapir Karli \\ Juan Alfredo Ayala-Haedo \\ William J Feuer \\ Maria Fernandez \\ Sander Dubovy \\ Sara T Wester \\ Bascom Palmer Eye Institute, \\ Miami, FL, USA
}

Correspondence: Sara T Wester Bascom Palmer Eye Institute, 900 NW 17th Street, Miami, FL 33136, USA

$\mathrm{Tel}+\mathrm{I} 3053266132$

Fax +l 3054824568

Email swester2@med.miami.edu
Purpose: To characterize the effect of prostaglandin analogs (PAs) on tissue specific expression of matrix metalloproteinases (MMPs) and tissue inhibitor of metalloproteinases (TIMPs) in levator aponeurosis resections (LAR) and conjunctiva-Muller muscle resections (CMMR).

Methods: Specimens from LAR and CMMR of PA users and non-users were analyzed for tissue specific expression of MMP-3, MMP-7, MMP-9 and TIMP-2 using immunohistochemistry. PA use, marginal reflex distances, levator function and palpebral fissure were documented through chart review. The associations between MMP expression, PA exposure time and ocular characteristics were evaluated with a two-factor analysis of variance and multiple correlation analysis. Results: We observed a tissue specific pattern of expression of MMPs and TIMP-2 in relation to PA exposure between CMMR and LAR specimens. There was increased MMP-7 and TIMP-2 expression in muscle compared to collagen and adipose tissue $(P \leq 0.005)$, as well as a statistically significant difference in the relationship of MMP-3, MMP-9 and TIMP-2 levels to PA exposure in the two types of muscles (all $P \leq 0.011$ ). Adipose tissue had a PA-dependent reduced expression of MMP-3 $(P<0.022)$, which was seen in both LAR and CMMR. Decreased expression of MMP-3 in collagen correlated with increased dermatochalasis $(P<0.045)$ and steatoblepharon $(P<0.018)$.

Conclusion: PA exposure may affect MMP and TIMP expression in a tissue specific manner, and decreased expression of certain MMPs in collagen correlates to increased clinical measures of prostaglandin associated periorbitopathy (PAP). Further studies with larger samples are needed to ascertain if the changes associated with PAP are due to MMP/TIMP changes or to structural changes.

Keywords: MMP, matrix metalloproteinase, prostaglandin associated periorbitopathy, PAP, prostaglandin analog, periorbitopathy

\section{Introduction}

Prostaglandin-F2-alpha and prostamide analogs (PAs) such as latanoprost (Pharmacia, Peapack, NJ, USA), travoprost (Alcon, Fort Worth, TX, USA) and bimatoprost (Allergan, Irvine, CA, USA) are a first line glaucoma therapy. Prostaglandin mediated AP-1 regulatory region activation within matrix metalloproteinase (MMP) promoters leads to alterations in MMP and tissue inhibitor of metalloproteinases (TIMP) levels. ${ }^{1}$ This activation is responsible for remodeling the extracellular matrix (ECM) and increasing uveoscleral outflow. ${ }^{1-3}$

MMPs and TIMPs remodel the ECM by modifying the structure and activity of substrates that are key players in maintaining ocular and periorbital physiology. ${ }^{4}$ 
Deregulation of MMP activity and MMP/TIMP ratio has been shown to play a role in many neurodegenerative diseases including macular degeneration, ${ }^{5}$ diabetic retinopathy, ${ }^{6}$ and ganglion cell death in glaucoma. ${ }^{7,8}$ Tissue specific patterns of enzyme expression may have implications in other ocular diseases as well.

Differential expression of MMPs and TIMPs has been demonstrated after PA exposure in various ocular tissues. PA exposure has been shown to increase MMP-1, MMP-3 and MMP-9 and decrease TIMP-1 and TIMP-2 in conjunctiva and tears. ${ }^{9,10}$ MMP-1 and MMP-9 increased and TIMP-1 decreased in corneal stroma ${ }^{10}$ and MMP-1, MMP-2, MMP-3 and MMP-9 increased in ciliary body smooth muscle (CBSM) after PA exposure. ${ }^{1,2}$ In Tenon capsule fibroblasts, MMP-3 and TIMP-2 expression increased following PA exposure. ${ }^{11}$ Previous studies show that increased MMP levels are related to increased fibrous tissue in pterygium epithelial cells ${ }^{12}$ and increased conjunctival scarring, ${ }^{13}$ indicating an effect of PAs on tissue ultrastructure which was exposure time dependent. ${ }^{2,9,14}$ This tissue specific pattern of expression of MMPs and TIMPs has not yet been demonstrated in levator and Mueller's muscles, which have been theorized as tissues affected by PAs. ${ }^{15-17}$

An association between the use of PAs and the development of prostaglandin associated periorbitopathy (PAP) ${ }^{15-23}$ was first reported in 2004. ${ }^{17,20}$ PAP is characterized as deepening of the upper eyelid sulcus, ${ }^{24}$ involution of dermatochalasis, orbital fat atrophy, enophthalmos, flattening of lower eyelid bags, inferior scleral show, tight orbits and ptosis. ${ }^{15,16}$ Many elements of PAP have been attributed to fat atrophy ${ }^{18,20,25}$ due to prostaglandin activation of mitogenactivated protein kinase and inhibitory phosphorylation of peroxisome proliferator-activated receptor gamma. ${ }^{26} \mathrm{MMPs}$ have been shown to influence the normal adipogenesis process in a variety of animal models. ${ }^{27-29}$ PAs may contribute to PAP through alterations of MMP/TIMP dynamics and subsequent ECM turnover. Ptosis has been documented in up to $7 \%$ of patients with PAP, ${ }^{18}$ and a dysregulation in the ECM scaffold could play a role in this process, as it has been previously shown to play a role in other eyelid malpositions. ${ }^{30,31}$

We hypothesized that there was a tissue specific pattern of expression of MMP and TIMP in tissues involved in PAP (muscle, collagen, adipose tissue). We suspected that the time of exposure to PA might influence the differential expression of MMPs in levator aponeurosis resection (LAR) and conjunctiva-Muller muscle resection (CMMR) specimens of patients on PAs with ptosis, and that the differential expression of MMPs may be associated with the clinical changes in PAP.

\section{Methods}

The study (IRB 20110692) was approved by the Institutional Review Board at the University of Miami and followed the tenets of the Declaration of Helsinki.

\section{Study population}

Patients undergoing ptosis repair were selected based on inclusion and exclusion criteria. Specimens of LAR and CMMR from previous ptosis repairs were also included. The treatment group included patients who had a history of PA use for 6 months or more in the operated eye. PA users were excluded if they had a condition that could cause ptosis unrelated to PA use or age. Controls included patients undergoing ptosis repair and who had no previous PA use. The PAP characteristics assessed in the study were previously validated by Tan and Berke. ${ }^{16}$

For prospective samples, written consent was obtained by the study personnel using an Institutional Review Board approved consent form. In addition, laboratory specimens of LAR and CMMR from previous ptosis repairs were included based on Institutional Review Board approval for retrospective analysis of laboratory samples. Three PA users and 4 PA non-users underwent LAR and CMMR (Table S1). Surgical specimens were sent to the pathology lab for sectioning and immunohistochemical staining with antibodies against MMP-3, MMP-7, MMP-9 and TIMP-2. These antibodies were selected based on previous data of the effect MMP's and TIMP's on ocular tissue as discussed above, as well as the availability of antibodies in the pathology lab and funding, given the preliminary nature of the study. Specimens obtained for retrospective review were selected based on the pathology lab diagnosis codes.

\section{Data extracted from medical records}

Medical records were reviewed and the following data were recorded: gender, age, type of glaucoma, type of PA, length of time of usage of PA, eye affected, marginal reflex distance 1 (MRD1), marginal reflex distance 2 (MRD2) and palpebral fissure $(\mathrm{PF})$.

\section{External photograph evaluation}

The principal investigator (STW) assessed and graded each external photograph for PAP characteristics (dermatochalasis and steatoblepharon) according to scales previously 
described by Shah et al. ${ }^{15}$ A masked, second independent grader was used to assess inter-grader reliability.

\section{Immunohistochemistry}

Surgical specimens were sent to the Florida Lions Ocular Pathology laboratory at Bascom Palmer Eye Institute. Specimens were fixed in formalin and microscopic glass slides were prepared. Sections were stained with H\&E. Immunohistochemistry was performed using the standard avidin-biotin-complex technique for antibodies against MMP-3, MMP-7, MMP-9 and TIMP-2. Grading of the staining intensity for epithelial, adipose, muscle, fibrous, nerve, glandular and lymphocytic tissue was performed by an ocular pathologist masked to the patients' clinical status. The intensity of the immunostaining was graded as none $(-, 0)$, mild $(+, 1)$, moderate $(++, 2)$, or strong $(+++, 3)$.

\section{Statistical analysis}

The affected eyes were analyzed individually. If multiple tissue samples were available for an affected eye, the scores of tissue specimen sections were averaged. The effects of the type of surgery (CMMR vs LAR) and prior use of PA (yes/no) on MMPs and TIMP-2 were analyzed with the two-factor analysis of variance. In a second set of ANCOVA models, the type of surgery was considered a factor and exposure time to PA was considered a covariate. Tests of interaction were used to evaluate whether exposure to PA had similar effects in both types of surgery. Multiple correlation analysis was used to quantify the associations between MMPs and TIMP-2 and orbital characteristics, adjusting for type of surgery and PA use. These analyses were performed for each tissue type. For those samples that had complete muscle, collagen and adipose expression measurements, differences in expression by tissue were analyzed with repeated measures of analysis of variance employing the Greenhouse-Geisser correction. Values with $P<0.05$ were considered statistically significant.

\section{Results \\ Demographics}

Demographics and percentage of patients on PAs based on exposure time are listed in Tables S2 and S3, respectively.

\section{Overall tissue specific differences in expression}

Overall differences in tissue specific expression of MMPs and TIMP could only be made on eight samples that had complete muscle, collagen and adipose measurements (Table S4).

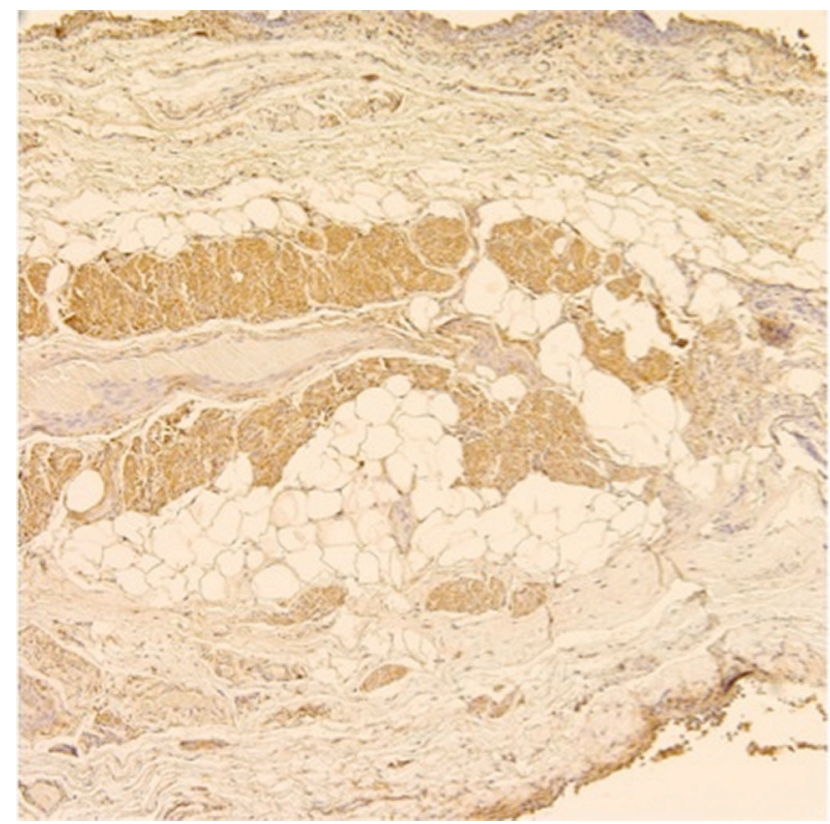

Figure I MMP-7 expression in CMMR (control).

Abbreviations: MMP, matrix metalloproteinases; CMMR, conjunctiva-Muller muscle resection.

Five $(63 \%)$ of these samples were CMMR and three were LAR (37\%). The breakdown between PA exposure and nonexposure was 4 in each group. Of the 4 with PA exposure, $1(13 \%)$ had $6-12$ months of PA exposure, and $3(38 \%)$ had $>6$ years of PA exposure. Statistically significant differences were observed between tissue types in MMP-7 and TIMP-2 expression. Post hoc least significant difference tests revealed that both MMP-7 and TIMP-2 had greater expression in muscle than in collagen or adipose $(P \leq 0.005)$ but that collagen and adipose were not different from each other. Figure 1 is a representative example showing MMP-7 expression in muscle.

\section{Effect of PA exposure on tissue specific MMP and TIMP expression}

Given the small sample size, there was no statistically significant difference in MMP/TIMP expression with PA exposure when either tissue samples from LAR or CMMR were considered separately, although a different expression distribution can be observed (Table 1 and Figure 2). MMP-9 and TIMP-2 had increased expression in muscle of LAR compared to CMMR in non-PA exposed patients (not statistically significant). ANCOVA analyses assessing the effects of PA exposure and type of surgery together revealed differences between specimens from LAR and CMMR in MMP and TIMP expression. These models were stronger, with respect to statistical significance, when including PA exposure time 
Table I Tissue specific and PA-dependent difference of MMP and TIMP expression (mean [SD]) in ocular tissue

\begin{tabular}{|c|c|c|c|c|c|c|}
\hline \multirow[t]{2}{*}{ Tissue } & \multirow[t]{2}{*}{ Protein } & \multicolumn{2}{|l|}{ CMMR } & \multicolumn{2}{|l|}{ LAR } & \multirow[t]{2}{*}{$P$-value } \\
\hline & & No PA & $\mathbf{P A}^{\mathbf{a}}$ & No PA & $\mathbf{P A}^{\mathbf{a}}$ & \\
\hline \multirow[t]{4}{*}{ Muscle } & MMP-3 & $1.9(0.6)$ & $2.0(0.0)$ & $2.0(0.0)$ & $0.5(0.7)$ & $0.011^{b}$ \\
\hline & MMP-7 & $2.6(0.5)$ & $2.7(0.6)$ & $2.5(0.7)$ & $2.0(0.0)$ & $>0.1$ \\
\hline & MMP-9 & $0.0(0.0)$ & $1.0(0.0)$ & $2.0(0.0)$ & $0.0(0.0)$ & $0.002^{b}$ \\
\hline & TIMP-2 & $1.3(0.5)$ & $1.7(0.6)$ & $2.0(0.0)$ & $0.5(0.7)$ & $0.002^{\mathrm{b}}$ \\
\hline \multirow[t]{4}{*}{ Adipose } & MMP-3 & I. $8(0.5)$ & $1.0(0.0)$ & $2.0(0.0)$ & I.3 (0.6) & $0.022^{c}$ \\
\hline & MMP-7 & $1.0(0.0)$ & I.0 (0.0) & $1.0(0.0)$ & I.0 (0.0) & $>0.9$ \\
\hline & MMP-9 & I.0 (0.0) & $1.0(0.0)$ & $1.0(0.0)$ & I.0 (0.0) & $>0.9$ \\
\hline & TIMP-2 & $0.3(0.5)$ & $0.0(0.0)$ & $0.0(0.0)$ & $0.0(0.0)$ & $>0.1$ \\
\hline
\end{tabular}

Notes: ${ }^{2}$ As noted in the text, PA exposure was analyzed as a covariate; however, for ease of presentation this table provides means without vs with any exposure to PA. 'Surgery type $\times$ time on PA interaction. 'Effect of time on PA, irrespective of surgery type.

Abbreviations: PA, prostaglandin analogs; MMP, matrix metalloproteinases; CMMR, conjunctiva-Muller muscle resection; LAR, levator aponeurosis resection; TIMP, tissue inhibitor of metalloproteinases.
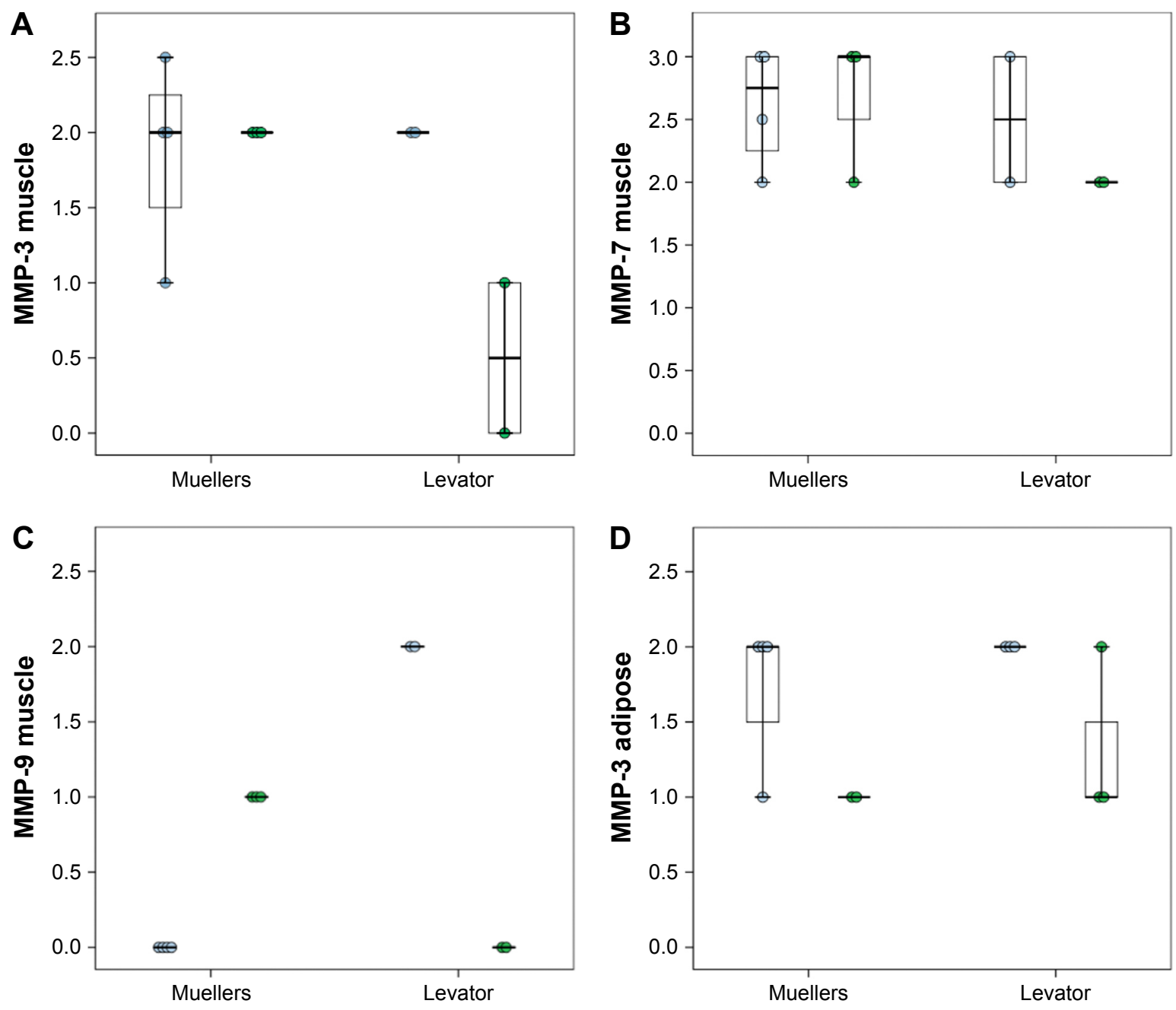

O No PA OPA

Figure 2 Effect of PA exposure on tissue specific MMP and TIMP expression.

Notes: (A) MMP-3 expression in Mueller's and levator muscles with and without PA exposure; (B) MMP-7 expression in Mueller's and levator muscles with and without PA exposure; (C) MMP-9 expression in Mueller's and levator muscles with and without PA exposure; (D) MMP-3 expression in adipose tissue of specimen from both LAR and CMMR with and without PA exposure.

Abbreviations: MMP, matrix metalloproteinases; CMMR, conjunctiva-Muller muscle resection; LAR, levator aponeurosis resection; PA, prostaglandin analogs. 
Table 2 Clinical characteristics correlation ${ }^{\mathrm{a}}$ with MMP and TIMP levels

\begin{tabular}{|l|l|l|l|l|l|l|}
\hline \multicolumn{2}{|l|}{ Control variables } & MRD2 & Dermatochalasis & Steatoblepharon & Inferior scleral show \\
\hline \multirow{2}{*}{$\begin{array}{l}\text { PA and } \\
\text { muscle }\end{array}$} & MMP-3 collagen & $\mathrm{r}$ & 0.220 & -0.613 & -0.694 & 0.255 \\
\cline { 3 - 7 } & $\mathrm{P}$ & 0.516 & 0.045 & 0.018 & 0.450 \\
\cline { 2 - 7 } & \multirow{3}{*}{ MMP-7 collagen } & $\mathrm{r}$ & 0.294 & -0.031 & -0.079 & 0.205 \\
\cline { 3 - 7 } & $\mathrm{P}$ & 0.380 & 0.927 & 0.818 & 0.545 \\
\cline { 2 - 7 } & \multirow{2}{*}{ MMP-9 collagen } & $\mathrm{r}$ & -0.682 & -0.124 & -0.039 & -0.552 \\
\cline { 3 - 7 } & & $\mathrm{P}$ & 0.021 & 0.716 & 0.909 & 0.078 \\
\hline
\end{tabular}

Note: a Partial correlation controlling for PA exposure and muscle sample.

Abbreviations: PA, prostaglandin analogs; MMP, matrix metalloproteinases; CMMR, conjunctiva-Muller muscle resection; LAR, levator aponeurosis resection; TIMP, tissue inhibitor of metalloproteinases; MRD, marginal reflex distance.

as a covariate, as opposed to including PA exposure as a dichotomous variable indicating the role of exposure time in the differences observed. With this analysis, there was a statistically significant difference in the relationship of MMP-3, MMP-9 and TIMP-2 levels to PA exposure in the two types of muscles (Table 1 , all $P \leq 0.011$ ). There was minimal difference between MMP-3 expression in CMMR and LAR muscle with exposure to PA but MMP-3 expression was reduced in LAR muscle exposed to PA (Table 1). For both MMP-9 and TIMP-2, expression was increased with PA in CMMR muscle but reduced in LAR muscle. There was no significant difference in MMP-7 levels. Adipose tissue from the samples had a statistically significant PAdependent reduced expression of MMP-3, which was not different between LAR and CMMR. There was no difference in other MMPs and TIMP levels between PA exposed and
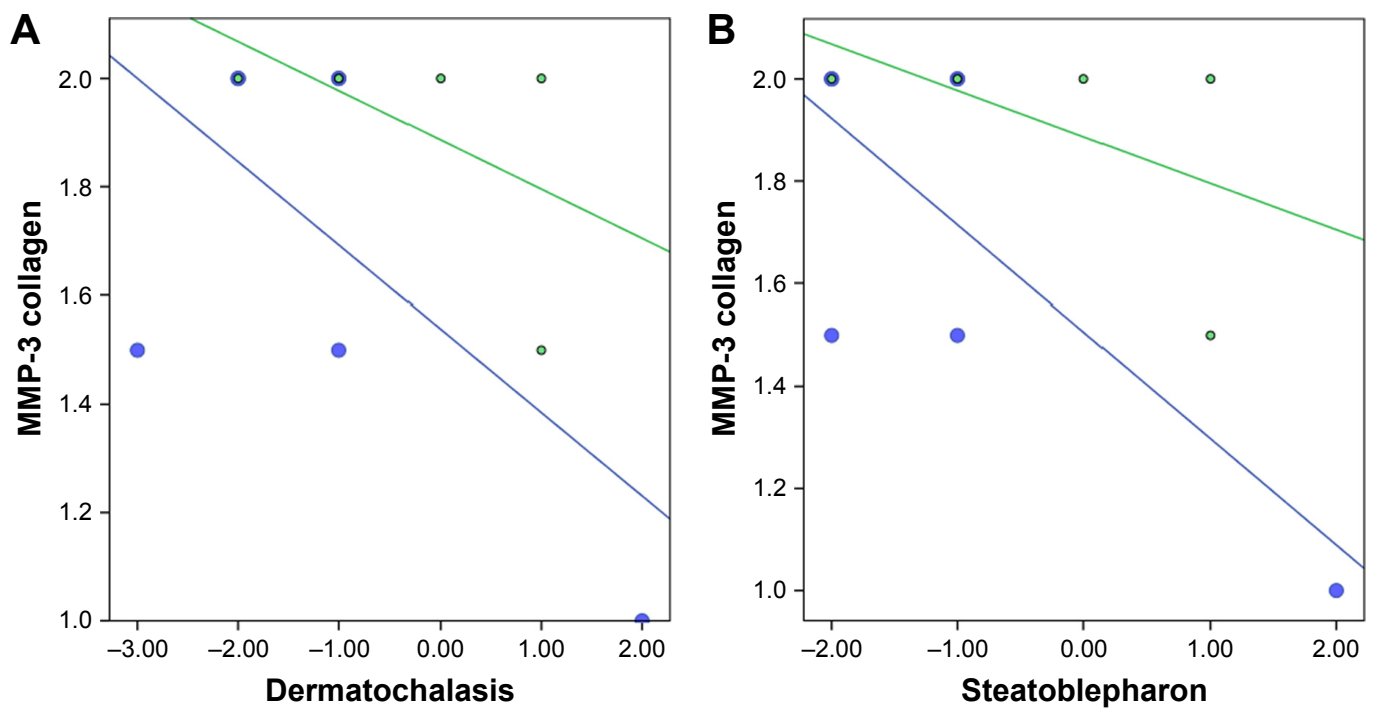

PA

- NoPA OPA $>$ NoPA $>$ PA

Figure 3 Clinical characteristics of PAP correlation with MMP and TIMP expression.

Notes: (A) MMP-3 levels in collagen negatively correlate with clinical findings of PAP based on dermatochalasis measurements in specimens from both LAR ("Levator") and CMMR ("Mueller"). (B) MMP-3 levels in collagen negatively correlate with clinical findings of PAP based on steatoblepharon measurements in specimens from both LAR and CMMR.

Abbreviations: PAP, prostaglandin associated periorbitopathy; MMP, matrix metalloproteinases; CMMR, conjunctiva-Muller muscle resection; LAR, levator aponeurosis resection; TIMP, tissue inhibitor of metalloproteinases. 
MMP-9 in collagen was negatively correlated to MRD2, which is a measure of eyelid retraction $(P<0.021)$, and positively correlated to MRD1 $(P<0.001)$, which is an inverse measure of ptosis (although MMP-3 was not correlated).

\section{Discussion}

PAs have been associated with PAP, with the aforementioned characteristics. Although fat atrophy is thought to influence PAP-associated characteristics, a dysregulation in the ECM scaffold has been postulated to play a role in this process as it has been previously shown to play a role in other eyelid malpositions. ${ }^{30,31}$

Inhibition of MMPs by TIMPs helps maintain balance in ECM metabolism and tissue remodeling. ${ }^{32}$ PAs exert part of their effect by remodeling of the scleral ECM, increasing uveoscleral and trabecular outflow. ${ }^{3}$ The intraocular pressure lowering is related to MMP and TIMP balance. ${ }^{1,2}$ Variable expression of MMPs and TIMPs occurs in different ocular tissues after PA exposure, and these enzymes have been previously localized to the epithelium, cornea, CBSM and tears. ${ }^{2,9,10} \mathrm{We}$ found increased MMP-7 and TIMP-2 expression in muscle tissue as compared to adipose and collagen. In addition, greater expression of TIMP-2 was seen in LAR controls than in CMMR controls, suggesting perhaps a higher baseline level of TIMP-2. When we then looked at alterations in MMP and TIMP levels in LAR and CMMR muscle specimens after exposure to PA, we found changes when analyzed by surgical specimen, suggesting that tissues may be affected differently due to differences in baseline expression.

Our findings suggest that MMP-3 and MMP-9 levels in levator muscle might decrease after PA exposure. This contradicts previous findings of increased MMP levels after PA exposure and may suggest that PAP-related changes in eyelid muscle may not be mediated by changes in MMP and TIMP levels within the levator muscle, although the small study size limits this assertion. Mueller's muscle specimens showed a statistically insignificant increased expression of MMP-9 and TIMP-2. It is possible that the absorption of the PAs is higher in Mueller's muscle given the anatomical proximity, and the changes in this tissue could account for ptosis. Controversy exists about whether the ptosis in patients with PAP is a true adverse effect of PAs or secondary due to changes in the surrounding tissue. The periocular changes could be secondary to PA-associated inflammatory changes, leading to perceived ptosis due to tight lids. ${ }^{15}$ The "ptosis" may be the result of increased eyelid margin tension with horizontal eyelid shortening and lateral canthal deformity/ displacement. ${ }^{33}$ Furthermore, ptosis in PA users could be secondary to the association of PAs with periorbital fat atrophy.

Fat atrophy is considered one of the leading changes in PAP. MMPs have been shown to influence the normal adipogenesis process in animal models. ${ }^{27-29}$ Research evaluating the role of MMPs in obesity has shown that MMP activity leads to increased levels of adipocyte ${ }^{27}$ while MMP inhibition leads to decreased adipogenesis. ${ }^{27,28}$ While MMP-2 in murine models has been shown to promote adipogenesis, inhibition of MMP-13 in vitro has been shown to suppress adipogenesis and suppression of MMP-9 in vitro and in vivo has been shown to have a dual effect on adipogenesis. ${ }^{27-29}$ We found that MMP-3 in adipose tissue was significantly reduced in PA users in both LAR and CMMR tissues.

While many elements of PAP have been attributed to fat atrophy, ${ }^{18,20,25}$ we did not find any association between MMP and TIMP levels of expression in adipose tissue and PAP characteristics. However, we found a correlation between the pattern of expression of MMP-3 in collagen (decreased MMP-3) and fat atrophy, involution of dermatochalasis and loss of lower eyelid fat pads. These findings suggest that ECM scaffold dysregulation may influence the development of PAP characteristics as seen in previous studies. ${ }^{31} \mathrm{We}$ did find a correlation between decreased MMP-9 staining and increased MRD2, which is a measure of inferior scleral show, and decreased MRD1 (associated with ptosis), both of which are elements of PAP.

While our findings suggest that PAP may be related to MMP/TIMP alterations in adipose and collagen tissue than in the muscle itself, the small sample size limits our findings and larger studies are needed to confirm these initial suggestions. Furthermore, immunohistochemistry may not be sensitive to detecting subtle differences in enzymatic levels. In addition, PAs may alter MMP activity rather than levels, as has been shown in studies of aqueous fluid. ${ }^{34}$ Change in enzymatic activity could possibly lead to elastin degradation changes such as those seen in floppy eyelid syndrome. ${ }^{31}$ Weinreb et al found that the increased levels of MMPs secreted from CBSM after PA exposure were largely present in their inactive pro-enzyme form. ${ }^{1}$ We did not assess pro-MMP levels and only analyzed the enzymes at one point in time. MMP/TIMP alterations may occur in an acute time frame with enzymatic levels returning to baseline. It is possible that there are other enzymes in inactive pro-molecular form induced by PA exposure, ${ }^{1}$ and that MMPs may not be the active players in PAP. This would also explain why the usual inverse relationship of MMP and TIMP levels is not seen in our study. Our results could also be limited by our 
analysis of pictures. We attempted to control a possible bias with independent observers and by using the picture analysis scales previously described in Shah et al. ${ }^{15}$

Further studies are needed to better elucidate the tissue specific changes of PAs on periocular tissue, which may enable modification of this medication to avoid the ocular side effect profile.

\section{Disclosure}

The authors report no conflicts of interest in this work.

\section{References}

1. Weinreb RN, Kashiwagi K, Kashiwagi F, Tsukahara S, Lindsey JD. Prostaglandins increase matrix metalloproteinase release from human ciliary smooth muscle cells. Invest Ophthalmol Vis Sci. 1997;38(13): 2772-2780.

2. Ooi YH, Oh DJ, Rhee DJ. Effect of bimatoprost, latanoprost, and unoprostone on matrix metalloproteinases and their inhibitors in human ciliary body smooth muscle cells. Invest Ophthalmol Vis Sci. 2009;50(11):5259-5265.

3. Lindsey JD, Kashiwagi K, Kashiwagi F, Weinreb RN. Prostaglandin action on ciliary smooth muscle extracellular matrix metabolism: implications for uveoscleral outflow. Surv Ophthalmol. 1997;41 Suppl 2: S53-S59.

4. Sivak JM, Fini ME. MMPs in the eye: emerging roles for matrix metalloproteinases in ocular physiology. Prog Retin Eye Res. 2002;21(1): $1-14$.

5. Plantner JJ, Jiang C, Smine A. Increase in interphotoreceptor matrix gelatinase A (MMP-2) associated with age-related macular degeneration. Exp Eye Res. 1998;67(6):637-645.

6. Das A, McGuire PG, Eriqat C, et al. Human diabetic neovascular membranes contain high levels of urokinase and metalloproteinase enzymes. Invest Ophthalmol Vis Sci. 1999;40(3):809-813.

7. De Groef L, Van Hove I, Dekeyster E, Stalmans I, Moons L. MMPs in the neuroretina and optic nerve: modulators of glaucoma pathogenesis and repair? Invest Ophthalmol Vis Sci. 2014;55(3):1953-1964.

8. Guo L, Moss SE, Alexander RA, Ali RR, Fitzke FW, Cordeiro MF. Retinal ganglion cell apoptosis in glaucoma is related to intraocular pressure and IOP-induced effects on extracellular matrix. Invest Ophthalmol Vis Sci. 2005;46(1):175-182.

9. Honda N, Miyai T, Nejima R, et al. Effect of latanoprost on the expression of matrix metalloproteinases and tissue inhibitor of metalloproteinase 1 on the ocular surface. Arch Ophthalmol. 2010;128(4):466-471.

10. Lopilly Park HY, Kim JH, Lee KM, Park CK. Effect of prostaglandin analogues on tear proteomics and expression of cytokines and matrix metalloproteinases in the conjunctiva and cornea. Exp Eye Res. 2012; 94(1):13-21.

11. Mietz H, Esser JM, Welsandt G, et al. Latanoprost stimulates secretion of matrix metalloproteinases in tenon fibroblasts both in vitro and in vivo. Invest Ophthalmol Vis Sci. 2003;44(12):5182-5188.

12. Di Girolamo N, McCluskey P, Lloyd A, Coroneo MT, Wakefield D. Expression of MMPs and TIMPs in human pterygia and cultured pterygium epithelial cells. Invest Ophthalmol Vis Sci. 2000;41(3): 671-679.

13. Kawashima Y, Saika S, Yamanaka O, Okada Y, Ohkawa K, Ohnishi Y. Immunolocalization of matrix metalloproteinases and tissue inhibitors of metalloproteinases in human subconjunctival tissues. Curr Eye Res. 1998;17(4):445-451.
14. Zhang SH, Zhao JL. Impact of combination use of $0.004 \%$ travoprost and $\%$ pilocarpine on matrix metalloproteinases synthesized by rabbit ciliary muscle: a pilot study. Chin Med Sci J. 2013;28(4):229-232.

15. Shah M, Lee G, Lefebvre DR, et al. A cross-sectional survey of the association between bilateral topical prostaglandin analogue use and ocular adnexal features. PLoS One. 2013;8(5):e61638.

16. Tan J, Berke S. Latanoprost-induced prostaglandin-associated periorbitopathy. Optom Vis Sci. 2013;90(9):e245-e247.

17. Peplinski LS, Albiani Smith K. Deepening of lid sulcus from topical bimatoprost therapy. Optom Vis Sci. 2004;81(8):574-577.

18. Kucukevcilioglu M, Bayer A, Uysal Y, Altinsoy HI. Prostaglandin associated periorbitopathy in patients using bimatoprost, latanoprost and travoprost. Clin Exp Ophthalmol. 2014;42(2):126-131.

19. Holló G. The side effects of the prostaglandin analogues. Expert Opin Drug Saf. 2007;6(1):45-52.

20. Filippopoulos T, Paula JS, Torun N, Hatton MP, Pasquale LR, Grosskreutz CL. Periorbital changes associated with topical bimatoprost. Ophthalmic Plast Reconstr Surg. 2008;24(4):302-307.

21. Park J, Cho HK, Moon JI. Changes to upper eyelid orbital fat from use of topical bimatoprost, travoprost, and latanoprost. Jpn J Ophthalmol. 2011;55(1):22-27.

22. Aihara M, Shirato S, Sakata R. Incidence of deepening of the upper eyelid sulcus after switching from latanoprost to bimatoprost. Jpn $J$ Ophthalmol. 2011;55(6):600-604.

23. Inoue K, Shiokawa M, Wakakura M, Tomita G. Deepening of the upper eyelid sulcus caused by 5 types of prostaglandin analogs. J Glaucoma. 2013;22(8):626-631.

24. Yang HK, Park KH, Kim TW, Kim DM. Deepening of eyelid superior sulcus during topical travoprost treatment. Jpn J Ophthalmol. 2009; 53(2):176-179.

25. Tappeiner C, Perren B, Iliev ME, Frueh BE, Goldblum D. Orbital fat atrophy in glaucoma patients treated with topical bimatoprost can bimatoprost cause enophthalmos? Klin Monbl Augenheilkd. 2008; 225(5):443-445.

26. Reginato MJ, Krakow SL, Bailey ST, Lazar MA. Prostaglandins promote and block adipogenesis through opposing effects on peroxisome proliferator-activated receptor gamma. J Biol Chem. 1998;273(4): $1855-1858$.

27. Van Hul M, Bauters D, Lijnen RH. Differential effects of a gelatinase inhibitor on adipocyte differentiation and adipose tissue development. Clin Exp Pharmacol Physiol. 2013;40(10):689-697.

28. Shih CL, Ajuwon KM. Inhibition of MMP-13 prevents diet-induced obesity in mice and suppresses adipogenesis in 3T3-L1 preadipocytes. Mol Biol Rep. 2015;42(7):1225-1232.

29. Bauters D, Scroyen I, Van Hul M, Lijnen HR. Gelatinase A (MMP-2) promotes murine adipogenesis. Biochim Biophys Acta. 1850;2015(7): 1449-1456.

30. Netland PA, Sugrue SP, Albert DM, Shore JW. Histopathologic features of the floppy eyelid syndrome. Involvement of tarsal elastin. Ophthalmology. 1994;101(1):174-181.

31. Schlötzer-Schrehardt U, Stojkovic M, Hofmann-Rummelt C, Cursiefen C, Kruse FE, Holbach LM. The Pathogenesis of floppy eyelid syndrome: involvement of matrix metalloproteinases in elastic fiber degradation. Ophthalmology. 2005;112(4):694-704.

32. Woessner JF Jr. Matrix metalloproteinases and their inhibitors in connective tissue remodeling. Faseb J. 1991;5(8):2145-2154.

33. Custer PL, Kent TL. Observations on Prostaglandin Orbitopathy. Ophthalmic Plast Reconstr Surg. 2016;32(2):102-105.

34. Pradhan ZS, Dalvi RA, Lai T, Kranemann C, Boyd S, Birt CM. Prostaglandin agonist effect on matrix metalloproteinase aqueous levels in glaucoma patients. Can J Ophthalmol. 2015;50(1):6-10. 


\section{Supplementary materials}

Table SI Type of surgery for PA treatment group and controls

\begin{tabular}{|l|l|l|l|}
\hline & $\begin{array}{l}\text { \# Treated } \\
\text { with PA }\end{array}$ & $\begin{array}{l}\text { \# Controls } \\
\text { (no PA treatment) }\end{array}$ & Total \\
\hline LAR & 3 & 4 & 7 \\
\hline CMMR & 3 & 4 & 7 \\
\hline Total & 6 & 8 & 14 \\
\hline
\end{tabular}

Abbreviations: PA, prostaglandin analogs; CMMR, conjunctiva-Muller muscle resection; LAR, levator aponeurosis resection.

Table S2 Demographics

\begin{tabular}{|c|c|c|}
\hline & $\begin{array}{l}\text { Controls } \\
\text { (no PA use) (\#) }\end{array}$ & $\begin{array}{l}\text { Subjects } \\
\text { (PA use) (\#) }\end{array}$ \\
\hline Mean age & 71 & 74 \\
\hline \multicolumn{3}{|l|}{ Gender } \\
\hline Females & 2 & 3 \\
\hline Males & 6 & 3 \\
\hline \multicolumn{3}{|l|}{ Eye affected } \\
\hline Right & 1 & 0 \\
\hline Left & 2 & 5 \\
\hline Bilateral & 5 & I \\
\hline \multicolumn{3}{|l|}{ Glaucoma } \\
\hline Open angle & 1 & 4 \\
\hline Pseudoexfoliation & 0 & 2 \\
\hline Chronic angle closure & 0 & 1 \\
\hline \multicolumn{3}{|l|}{ Prostaglandin analog } \\
\hline Latanoprost & 0 & 2 \\
\hline Bimatoprost & 0 & 1 \\
\hline Travoprost & 0 & 3 \\
\hline \multicolumn{3}{|l|}{ Time on PA } \\
\hline$<6$ months & 0 & 0 \\
\hline 6-12 months & 0 & 2 \\
\hline $1-3$ years & 0 & 1 \\
\hline $3-6$ years & 0 & 0 \\
\hline$>6$ years & 0 & 3 \\
\hline CMMR & 4 & 3 \\
\hline LAR & 4 & 3 \\
\hline
\end{tabular}

Abbreviations: PA, prostaglandin analogs; CMMR, conjunctiva-Muller muscle resection; LAR, levator aponeurosis resection.

Clinical Ophthalmology

\section{Publish your work in this journal}

Clinical Ophthalmology is an international, peer-reviewed journal covering all subspecialties within ophthalmology. Key topics include: Optometry; Visual science; Pharmacology and drug therapy in eye diseases; Basic Sciences; Primary and Secondary eye care; Patient Safety and Quality of Care Improvements. This journal is indexed on

Submit your manuscript here: http://www.dovepress.com/clinical-ophthalmology-journal
Table S3 Time on PA

\begin{tabular}{|l|l|l|}
\hline Time on PA & Number & Percent \\
\hline 0.0 & 8 & 57.1 \\
\hline 2.0 & 2 & 14.3 \\
\hline 3.0 & 1 & 7.1 \\
\hline 5.0 & 3 & 21.4 \\
\hline
\end{tabular}

Notes: Scale: $0=$ never (control); $\mathrm{I}=<6$ months; $2=6-12$ months; $3=\mathrm{I}-3$ years; $4=3-6$ years; $5=>6$ years.

Abbreviation: PA, prostaglandin analogs.

Table S4 Tissue specific differences in expression (SD)

\begin{tabular}{|l|l|l|l|l|}
\hline & Muscle & Collagen & Adipose & P-value \\
\hline MMP-3 & $1.69(0.80)$ & $1.88(0.23)$ & $1.38(0.52)$ & 0.157 \\
\hline MMP-7 & $2.44(0.50)$ & $\mathrm{I} .06(0.18)$ & $1.00(0.00)$ & $<0.00 \mathrm{I}$ \\
\hline MMP-9 & $0.50(0.76)$ & $0.13(0.35)$ & $0.00(0.00)$ & 0.183 \\
\hline TIMP-2 & $1.38(0.74)$ & $0.13(0.35)$ & $0.13(0.35)$ & 0.005 \\
\hline
\end{tabular}

Abbreviations: MMP, matrix metalloproteinases; TIMP, tissue inhibitor of metalloproteinases.

\section{Dovepress}

PubMed Central and CAS, and is the official journal of The Society of Clinical Ophthalmology (SCO). The manuscript management system is completely online and includes a very quick and fair peer-review system, which is all easy to use. Visit http://www.dovepress.com/ testimonials.php to read real quotes from published authors. 